\title{
A new control strategy for the composting process based on the oxygen uptake rate
}

Belén Puyuelo, Teresa Gea*, Antoni Sánchez

Composting Research Group. Department of Chemical Engineering, Escola d'Enginyeria,

Universitat Autònoma de Barcelona, 08913-Bellaterra (Barcelona), Spain.

*Corresponding author: Tel.: +34 935811879, Fax: +34 935812013

E-mail address: teresa.gea@uab.cat (T. Gea)

Pre-print of: Puyuelo, B.; Gea, T. and Sánchez, A. "A new control strategy for the composting process based on the oxygen uptake rate" in Chemical engineering journal (Ed. Elsevier), vol. 165, issue 1 (Nov. 2010), p. 161-169. The final version is available at DOI 10.1016/j.cej.2010.09.011 


\begin{abstract}
Up to now different control strategies to supply the oxygen requirements to the composting process have been studied. All of them seek for the biological activity optimization. In general, temperature and oxygen content are identified as the key parameters to assess the microbial activity. For this reason, the most favorable range of temperature and oxygen content for composting has frequently been studied and used as controllers' set points. On contrast, no previous works have studied the feasibility of oxygen supply according to the biological activity during the process, measured as oxygen uptake rate. In this field, a new automatic composting controller has been developed using the oxygen uptake rate measure as the measured variable. After setting up and to start-up this new technique, two pilot composting trials were undertaken with municipal solid waste. Oxygen, temperature and cyclic controllers were also implemented and tested in the composting of the same waste, in order to compare the results and to determine what the optimum system is. The four systems studied had similar temperature profiles, whereas except for the new controller, the oxygen content was constantly oscillating during most part of the process due to severe airflow changes. Through all the most relevant parameters determined, it can be observed that the new controller offers the most optimum system performance, since with low energy consumption a higher total oxygen uptake is achieved and, in consequence, the most stable end-product is obtained. Hence, the oxygen uptake rate controller is recommended for the airflow regulation in composting systems with automatic control.
\end{abstract}

\title{
Keywords
}

Oxygen Uptake Rate, Optimization, Composting, Process Control, Airflow, Residence Time Distribution. 


\section{Introduction}

Composting is an aerobic thermophilic biodegradation process, which requires oxygen to stabilize the organic wastes and optimal moisture content for the microorganisms' development [1]. Today, different composting technologies are applied in industrial facilities. The method selection is dependent on the investment and operation cost, time required to reach compost stability and maturity, the availability of land and origin of raw materials [2]. Among the available methods for composting, closed vessel technologies, as the tunnel technology, can be defined as the most sophisticated and environmentally controlled systems, and are successfully implemented as high capacity facilities in populated areas. On contrast, the open-air pile system is the simplest and requires the lowest investment [1].

In order to achieve a successful composting, the influencing factors on the biological activity such as temperature, moisture content, aeration rate, $\mathrm{pH}, \mathrm{C} / \mathrm{N}$ ratio, and composting material must be appropriately controlled [3]. Among all these factors, the aeration rate is defined by Diaz et al. [4] as the most important parameter for the composting process. This provides oxygen, essential to avoid the anaerobic conditions and to carry out the aerobic decomposition of the organic matter. Because of that, the aeration affects microbial activity, substrate degradation rate and temperature variation of the process [5]. Moreover, ventilation velocity can help increasing the degree of aerobiosis, and consequently the reaction rate, by promoting a greater oxygen diffusion at the biofilm [6].

In general, the main aeration methods providing oxygen during composting are: physical turning of the mass, natural convection and forced aeration [7]. In previous studies, different forced aeration ranges have been recommended for specific wastes due to the different composition in terms of biodegradability. Even, Rasapoor et al. [8] proposed different ranges depending on the stage of the process for avoiding too high or insufficient oxygen level. In most of the composting plants a minimum (usually off) and a maximum airflow are established. In some facilities the airflow is provided in fixed cycles, e.g. $5 \mathrm{~min}$ on and $30 \mathrm{~min}$ off at first and 5 min on and 60 min off after 50 days of process [2]. Sometimes, oxygen is supplied as a function of average mass temperature or oxygen concentration in the exhaust gases via feedback control 
[9-11], assuming that they are the main factors indicative of microbiological activity. Both factors have also been implemented together in a close loop feedback control studied [12].

Temperature controllers are based on the removal of excess heat accumulated in the composting matrix due to the microbial metabolism. In most cases, by satisfying the needs of the temperature criteria, the oxygen requirement is also met [13-16]. Many studies have stated the influence of the temperature on the composting process. Usually, the temperature threshold selected is found in the range of 50 to $60^{\circ} \mathrm{C}$. MacGregor et al. [17] found that decomposition was maximized in the temperature range between 52 and $60{ }^{\circ} \mathrm{C}$. Other authors suggested that the optimum temperature for decomposition ranging from 35 to $60{ }^{\circ} \mathrm{C}[5,18]$ or from 40 to $70{ }^{\circ} \mathrm{C}$ $[1,19]$. Liang et al. [20] concluded that the effect of the temperature on the biological activity is less influential than the moisture content which on the other hand is greatly affected by the aeration rate. They suggested that the enhancement of the microbial activities induced by temperature increment can also be achieved by increasing moisture content alone. Temperatures up to $55^{\circ} \mathrm{C}$ for 3 consecutive days or longer have been stated [21] to guarantee the pathogen elimination and meet a free pathogen end-product. It must be noted that if temperature reaches $82{ }^{\circ} \mathrm{C}$, the microbial community can be hindered [20]. Later on, Bustamante et al. [22] concluded that the occurrence of relatively high thermal values during the composting process does not always ensure a complete sanitation of the end-product. Besides the study of the optimum temperature, some works have also reported the best localization of the thermocouple used $[12,14,16,22]$. In energy terms, a higher set point was recommended if the thermocouple was located in the upper layers. On contrast, a lower temperature gradient among the layers of the material can be observed when inserting the sensor in the lower layers [16].

Oxygen feedback controllers have also been used to enhance the composting process, since the oxygen content is an essential requirement to develop the biological activity under aerobic conditions. Several ranges of oxygen concentration in the exhaust gases have been also recommended. It has been stated that oxygen levels between 5 and $20(\% \mathrm{v} / \mathrm{v})$ result in an optimum range [24]. Magalhaes et al. [25] affirmed that the presence of oxygen in the outgoing gases should be maintained between 10 and $18 \%$ to optimize the biological activity. Also it has 
been demonstrated that the composting process can be undertaken correctly by means of oxygen concentration between 15 and 20\% [26]. Others authors commented that during the thermophilic conditions, the optimum oxygen range decreased [27]. On the other hand, according to [28] a microaerobic environment with enough dissolved oxygen available for microorganism in a liquid biofilm provides a more effective biodegradation than a macroaerobic environment with high oxygen content in the gas phase. However, it is only possible to measure the biological activity through the oxygen content in the exhaust gases. In either case, oxygen gas levels neither above $15 \%$ nor below $5 \%$ are globally recommended. Oxygen levels under $5 \%$ can cause anaerobic conditions, whereas levels over $15 \%$ are indicative of excessive aeration which tends to cool the material [29].

Other more complex strategies and model-based advanced controllers have been suggested in literature for bioreactors [30] and specifically for the composting process [6, 31]. Certainly these are promising options for complex biological processes controlling but are hard to implement in real operating plants at industrial scale.

In any case, all the composting control strategies to regulate the airflow supply have a common goal. All of them have been developed to improve the biological activity and thus, the overall reaction rate, based on its main indicative parameters (temperature, degree of aerobiosis, etc.). Nevertheless, the study of a new feedback strategy based in the measure of the biological activity would provide a more reliable and robust system control. Biological activity, or reaction rate, has been highlighted as one of the potential controlled parameters suitable for a composting control system [6]. Respiration rate would be the best indicator of reaction rate. Thereby, the key factor of the composting process (i.e., the biological activity) would be monitored and optimized through the continuous measure of the Oxygen Uptake Rate (OUR).

Therefore, the main goals raised in this research are: i) to develop a new composting control strategy based on the OUR on-line measure; ii) to implement the OUR control in a pilot-reactor to undertake the composting process and iii) to compare the results obtained with the typical composting controllers used. 


\section{Materials and Methods}

\subsection{Composting Pilot Reactor}

The results presented in this work were obtained from five composting experiments in which different airflow regulation systems were applied. All of them were conducted at pilot scale using an adiabatic cylindrical reactor with an operating volume of $50 \mathrm{~L}$. Approximately $25 \mathrm{~kg}$ of the waste selected were treated in each experiment. Two geometrically identical reactors were used in parallel. A scheme of one pilot reactor set up can be seen on Fig. 1.

The reactor walls were thermally isolated with polyurethane foam in order to avoid heat losses. A perforated plate was fitted into the bottom of the reactor to support the material, to help leachate removal and to optimize the airflow circulation. Two orifices were situated at the bottom cover of the reactor, one to introduce air from a compressor and other for leachate removal. Two more orifices were situated at the top cover. One hole was to insert the Pt-100 sensor for temperature monitoring (Desin Instruments, Barcelona, Spain), which was placed at middle height of the material matrix. The other orifice was used to remove the exhaust gases in order to analyze the oxygen concentration. Before the oxygen sensor (Xgard, Crown, UK) a water trap by refrigeration was placed to avoid wet gases passing through the gas analyzer.

The data acquisition and control system was composed by an acquisition chassis (cDAQ9172, National Instruments, USA) connected to a PC and using LabView 8.6 software (National Instruments, USA). Temperature, outgoing oxygen gas concentration, and inlet airflow were the parameters monitored during the experimental trials. Temperature probe and oxygen sensor were connected to the data acquisition chassis. Instead, the input and output electrical signals of the flow meter were directly connected to the PC through an RS-232 serial port. All the data were recorded and shown in a graph or in the program interface from which different control systems could be programmed.

\subsection{Composting material}


The waste used in all these experiments was source-selected Organic Fraction of Municipal Solid Waste (OFMSW) mixed with pruning waste as a bulking agent. The mixture (with a volumetric ratio 1 to 1) was collected in a composting plant located in Manresa (Barcelona, Spain). A total of $200 \mathrm{~kg}$ were collected in order to carry out the experiments with the same material. After collection, an homogeneous sample was used for waste characterization and all the remaining waste was frozen at $-18{ }^{\circ} \mathrm{C}$. Before starting-up each composting experiment, the material was removed from the freezer and defrosted in the laboratory at room temperature for 24 hours. It is important to note that the five experiments presented in this paper were undertaken in a total period of three months following the sample freezing. In this period, it was considered that the biological activity of the waste was not modified by the different freezing time.

\subsection{Parameters evaluated}

A visual comparison among the controllers performance was undertaken from the profiles of temperature, oxygen composition in the outgoing gases and Oxygen Uptake Rate (OUR).

In order to do a quantitative evaluation of the control systems, different biological and economic variables were determined. Maximum oxygen uptake rate $\left(\mathrm{OUR}_{\max }\right)$ achieved, total cumulative oxygen consumption $\left(\mathrm{AT}_{\mathrm{u}}\right)$ and total energetic consumption were variables calculated during the experiments. Additionally the initial and final material stability degree was evaluated for each composting experiment by determining the corresponding DRI (Dynamic Respiration Index) [32]. This measure was undertaken from a representative sample after mixing vigorously the final material in the reactor.

\subsubsection{Oxygen Uptake Rate and total cumulative oxygen consumption}

Experimental measure of OUR was indirectly determined on-line with empirical data on airflow and oxygen using equation (4) deduced from the mass balance in steady-state.

$$
\text { OUR }=F \cdot\left(0.209-y_{O_{2(M L)}}\right) \cdot \frac{P \cdot 32 \cdot 60}{R \cdot T}
$$


where: OUR is the Oxygen Uptake Rate $\left(\mathrm{g} \mathrm{O}_{2} \mathrm{~h}^{-1}\right) ; F$, airflow into the reactor $\left(\mathrm{L} \mathrm{min}^{-1}\right)$; $\mathrm{Y}_{\mathrm{O} 2 \mathrm{ML}}$, is the logarithmic mean between the oxygen molar fraction in the exhaust gases and the inlet air $\left(\mathrm{mol} \mathrm{O}_{2} \mathrm{~mol}^{-1}\right) ; P$, pressure of the system assumed constant at $101325 \mathrm{~Pa} ; 32$, oxygen molecular weight $\left(\mathrm{g} \mathrm{O}_{2} \mathrm{~mol} \mathrm{O}_{2}^{-1}\right) ; 60$, conversion factor from minute to hour; $R$, ideal gas constant $\left(8310 \mathrm{~Pa} \mathrm{~L} \mathrm{~K}^{-1} \mathrm{~mol}^{-1}\right)$; $T$, temperature at which $\mathrm{F}$ is measured $(\mathrm{K})$.

Total cumulative consumption $\left(\mathrm{AT}_{\mathrm{u}}\right)$ was determined through the continuous OUR data obtained along both OUR-controller experiments. It was calculated according the equation 5:

$$
A T_{u}=\int_{0}^{t} O U R_{t} d t
$$

where: $A T_{u}$, is the total oxygen consumed between time 0 to $\mathrm{t}\left(\mathrm{g} \mathrm{O}_{2}\right)$; $t$, the final experimental time (h); OUR, the oxygen uptake rate measured in the steady state $\left(\mathrm{g} \mathrm{O}_{2} \mathrm{~h}^{-1}\right)$ for each cycle. It is important to note that, except for the OUR controllers, the OUR measure could not be determined during all the process because the cycle time programmed was insufficient to reach the steady conditions. Despite this, the $\mathrm{AT}_{\mathrm{u}}$ value could be estimated for the temperature and oxygen controllers from the difference between total oxygen in and total oxygen out the reactor considering total experimental time.

\subsubsection{Energy consumption}

The total energy consumed in each experiment was estimated from total airflow supply. It was determined in $\mathrm{kJ}$ units applying a conversion factor $\left(396 \mathrm{KJ} \mathrm{m}^{-3}\right)$ to transform the total $\mathrm{m}^{3}$ of air supplied to the total energy consumed by the compressor.

\subsubsection{Stability degree}

Based in the methodology proposed by [33] to assess biological stability degree, the Dynamic Respiration Index was measured in the respirometer built and start-up by Ponsá et al. [32]. Briefly, it consists on placing $150 \mathrm{~g}$ of sample in an Erlenmeyer flask of $500 \mathrm{~mL}$ of total capacity and incubating in a bath water at $37^{\circ} \mathrm{C}$. Next, a constant airflow is supplied through the sample and the oxygen content in the outgoing gases is measured. From this assay, the Dynamic 
Respiration Index (DRI) was determined as the maximum average value of OUR measured during the 24 hours. It is expressed in $\mathrm{mg} \mathrm{O}_{2} \mathrm{~g} \mathrm{OM}^{-1} \mathrm{~h}^{-1}$. Duplicates of all samples were analyzed and a third replicated was undertaken when deviation among duplicates was more than $20 \%[32]$.

\subsection{Composting controllers}

Four different control strategies were studied and are described below. In all cases, airflow was used as the manipulative variable. Three different closed-loop controllers and a fourth system based on a timed ON-OFF control configuration were tested. The lowest airflow applied at the reactor was never below $0.2 \mathrm{~L} \mathrm{~min}^{-1}\left(8 \cdot 10^{-3} \mathrm{~L} \mathrm{~min}^{-1} \mathrm{~kg}^{-1}\right.$ total mass $)$ to overcome the pressure drop of the reactor and to obtain a constant outgoing gas flow for oxygen monitoring purposes. Experimentally, each control strategy was applied in a 20 days composting experiment. This trial length was considered representative of the overall composting process evolution.

\subsubsection{Oxygen feedback control}

The controller was based on the airflow manipulation by means of the oxygen content measured in the exhaust gas. It was necessary to establish an $\mathrm{O}_{2}$ set point to maintain the system in favorable conditions. From the literature found, the oxygen set point was fixed between 11.5 and $12.5 \%(\mathrm{v} / \mathrm{v})$. Emulating the controllers used at industrial level, the controller applied a high flow for oxygen levels below $11.5 \%$ and a low flow for measures over $12.5 \%$, whereas the controller did not take action when the measure was within this range. The highest and lowest flows predetermined were 3 and $0.2 \mathrm{~L} \mathrm{~min}^{-1}$, respectively. Because of the system's slow dynamics the closed loop applied was set up to work in cycles of 15 minutes. According to the RTD analysis undertaken this time was over the average residence time for the selected high airflow.

\subsubsection{Temperature feedback control}


The structure of this loop was similar to the oxygen controller but replacing the oxygen measure by the temperature achieved in the center of the composting mass. In 15 minutes cycles, high airflow $\left(4 \mathrm{~L} \mathrm{~min}^{-1}\right)$ was activated when the temperature measure was above $55.5^{\circ} \mathrm{C}$, whereas a low flow (1 $\mathrm{L} \mathrm{min}^{-1}$ and $0.5 \mathrm{~L} \mathrm{~min}^{-1}$ during the last six days) was applied when temperature was below $54.5^{\circ} \mathrm{C}$.

\subsubsection{Airflow regulation by predetermined cycles}

This is the most extended aeration system in aerated windrow facilities. In this case, inlet airflow was regulated automatically by predetermined timed cycles. Basing on the study presented by [2], the airflow regulation was provided in cycles of $5 \mathrm{~min}$ at $5 \mathrm{~L} \mathrm{~min}^{-1}$ and $25 \mathrm{~min}$ at $0.2 \mathrm{~L} \mathrm{~min}^{-1}$.

\subsubsection{Oxygen Uptake Rate feedback control}

Two composting experiments were undertaken with the new control strategy developed to verify the reproducibility of the system. The main objective of this controller was to obtain an automatic airflow regulation in order to achieve the maximum measure of the biological activity (OUR). The system performed in cycles of 1 hour according to the RTD study to ensure the measure of OUR under pseudo-steady state conditions. The designed OUR control loop compares the variations reached among the successive cycles OUR measures according to the airflow applied. The average value of OUR calculated during the last 10 minutes of each cycle was used.

During the start-up, different control laws were studied and tested for all possible situations (data not presented). Finally, a higher OUR optimization was found with the specific laws shown as a flowchart in the Fig. 2. The final algorithm consists on the following steps: Firstly, after completing the $\mathrm{n}$ cycle, the oxygen level is revised to avoid percentages below $5 \%$ $(\mathrm{v} / \mathrm{v})$. If this level is below this limit, airflow will be increased by $50 \%$. This minimum $5 \%$ oxygen level is established as a "security threshold" to avoid anaerobiosis in the process in case the OUR fails to maintain a proper oxygen level. If an adequate oxygen level is measured, the 
system will start the OUR-based control loop which will establish the airflow based on the OUR measure and the comparison of flow applied among two consecutive cycles as follows: For both parameters, OUR and airflow, three situations are possible, i.e. the system determines if the current value is lower than, higher than or equal to the previous. It is important to note that different absolute thresholds were established to define the superior and inferior limit in which the variation of OUR and airflow can be considered negligible. The limit to detect an OUR variation was defined as $0.5 \%$ of the maximum OUR achieved in previous experiments (about $\left.15 \mathrm{~g} \mathrm{O}_{2} \mathrm{~h}^{-1}\right)$. Instead, the range considered for the airflow measures was $0.05 \mathrm{~L} \mathrm{~min}^{-1}$. Considering this, the controller checks the OUR variation. Next, it contrasts if the OUR variation obtained is linked with an increase, decrease or a constant airflow. From this algorithm proposed, the system regulates the necessary inlet airflow to optimize the OUR achieved along the process.

To start up the control strategy, two initial parameters have to be fixed, i.e. OUR $\mathrm{R}_{\mathrm{n}-1}$ and $\mathrm{F}_{\mathrm{n}-1}$. Flow and OUR set to time zero are the initial values with which the first cycle results are compared. To minimize the energetic consumption, the initial airflow fixed was the lowest, i.e. $0.2 \mathrm{~L} \mathrm{~min}^{-1}$. The initial OUR fixed was 0.1 to force an increase airflow after the first cycle.

\subsection{Analytical Methods}

Dry Matter (DM), total Organic Matter (OM) and Total Organic Carbon (TOC) were determined according to the standard procedures [34].

Air Filled Porosity (AFP) is the air volumetric fraction in a solid matrix. AFP in the reactor was measured using a self made constant volume air pycnometer connected to the reactor, which allowed for AFP determination in-situ, according to the description in [35]. It is expressed as the volumetric ratio of pore filled with gas to total sample volume. AFP was checked in each trial after systematical filling of the reactor to ensure reproducibility of initial matrix conditions among experiments [36].

\subsection{Reactor Model Flow}


The model flow of the solid bed reactor was determined by the Residence Time Distribution (RTD) method [37]. It consists in a tracing method, which measures the signal response modification respect to the entering flow signal.

The oxygen present in air was the tracer gas selected for the RTD determination in the reactor because it is easily detectable. This tracer fluid can not be considered inert as it can be consumed by the biomass present in the organic bed. For this reason, stabilized compost with a negligible oxygen consumption (confirmed by respirometry, DRI lower than $0.5 \mathrm{mg} \mathrm{O}_{2} \mathrm{~g} \mathrm{OM}^{-1}$ $\mathrm{h}^{-1}$ ) was used like a solid bed. The composted material used in the tracing experiments had a AFP similar to the OFMSW employed in the composting experiments. Thus, the airflow pattern obtained by RTD was assumed equivalent to the pattern found in later OFMSW composting experiments.

A tracer step input was studied for different air flows. Initially, a constant pure nitrogen flow was introduced until negligible oxygen concentration was detected in the outgoing gas. Then, the nitrogen flow was replaced by the same flow of clean air (composed by 20.9 volumetric percentage of oxygen) and the oxygen sensor monitored the tracer concentration at the outlet of the reactor. From the numerical derivation of the signal response evolution the E curve (commonly known as RTD curve) could be obtained.

For each RTD curve, the mean residence time $\left(t_{m}\right)$ and the variance $\left(\sigma^{2}\right)$ were calculated (equation 1 and 2). According to the Van der Laan theory [38] (equation 3) for the closedvessels [37], these measures are directly linked with the axial dispersion coefficient (D/uL) from plug flow models. Thus, negligible dispersion to the ideal plug flow are determined by a near to zero D/uL coefficients.

$$
\begin{aligned}
t_{m} & =\frac{\int_{0}^{\infty} t C d t}{\int_{0}^{\infty} C d t} \\
\sigma^{2} & =\frac{\int_{0}^{\infty} t^{2} C d t}{\int_{0}^{\infty} C d t}-t_{m}^{2}
\end{aligned}
$$




$$
\sigma_{\theta}^{2}=\frac{\sigma^{2}}{t_{m}^{2}}=2\left(\frac{D}{u L}\right)-2\left(\frac{D}{u L}\right)^{2}\left[1-e^{-u L / D}\right]
$$

where $\mathrm{C}$ is the tracer concentration for each time $(\mathrm{t})$.

\section{Results and discussion}

\subsection{Gas Flow Modeling}

In order to know the flow pattern of the composting system, six tracing experiments were undertaken at different airflows within the usual system range in composting pilot experiments. Experimental RTD curves for filled-to-top reactor are shown in Fig. 3 (results for airflow 8 L $\min ^{-1}$ are not presented for the figure better understanding). As can be seen, the RTD curve peak was thinner and higher when the airflow increased. In addition, an airflow increase produced a closer RTD curve to the symmetrical peak, which characterizes a plug flow. In fact, any curve presented the negative exponential trend associated to the mixed flow. Thus, the RTD curves obtained could be assimilated to the flow pattern of the plug axial dispersion flow. However, as the airflow decreased, the flow pattern was far from the ideal plug-flow due to the increase in axial dispersion, as reflected the wider and lower peaks.

Table 1 shows the three characteristic parameters of RTD characterization: mean residence time, $\mathrm{t}_{\mathrm{m}}$; variance, $\sigma^{2}$; and dispersion coefficient, D/uL, obtained from RTD curves and dispersion model methods. As expected, these three parameters decreased when airflow increased. The evaluation of the dispersion coefficient confirmed the assumption that the reactors worked following the plug flow model with axial dispersion, which increases for low flows. According to this model, in the absence of gas complete mix there exists an oxygen gradient along the reactor, and thus the oxygen content in the reactor could be expressed as the logarithmic mean concentration among the outlet and inlet gases [39].

To simulate the different conditions of the composting trials, the tracer experiments were also undertaken with the reactor filled at $80 \%$ of its total capacity. This additional RTD study was undertaken to analyze the effect of headspace in the airflow pattern. Tremier et al. [40, 41] 
found that the headspace in the composting reactor was better modeled by a mixed flow pattern. To illustrate results, Fig. 4 presents the RTD curves obtained for a low and a high airflow with the reactor filled up to $80 \%$ and $100 \%$. From the behavior observed together with the dispersion coefficient analysis it could be concluded that flow pattern was not altered by the headspace volume.

\subsection{Chemical properties of the initial and composted waste}

The main chemical characteristics of the OFMSW collected and the different final products obtained after the composting experiments are shown in Table 2. The initial properties were analyzed in a representative sample before freezing all the waste collected. These data were taken as the initial characterization for all the experiments. Temperature controller led to the lowest OM reduction. Final products obtained in the OUR controllers trials showed the lowest organic matter and TOC contents. On the other hand, the physical structure of the waste used presented a $63 \%$ AFP, similar to the AFP value of the solid bed used in the tracing experiments (compost, $55 \%$ AFP).

\subsection{Oxygen controller}

Fig. 5(a) shows the resultant temperature profiles and airflow rates during the composting experiment with airflow regulation based in an oxygen feedback loop. The OUR obtained with a constant airflow applied during the high-rate stage is also presented. It can be seen, after the first day of the process the thermophilic temperatures range (over $45^{\circ} \mathrm{C}$ ) was achieved. The temperature reached $70{ }^{\circ} \mathrm{C}$ and remained in the range of $60-70{ }^{\circ} \mathrm{C}$ during the 10 days following. At first in this stage, the oxygen content was under the threshold recommended (below 5\%), since the presence of readily biodegradable materials caused a high oxygen consumption. As a consequence, from day 1 to almost day 4, the airflow was fixed at the maximum rate. This allowed to measure the oxygen content in steady-state conditions and to determine the OUR profile during the stage where the maximum consumption was achieved (see Fig.5(a)). Next, the oxygen percentage began to recover and the airflow was constantly switching from 3 to $0.2 \mathrm{~L}$ 
$\min ^{-1}$. Airflow fluctuations produced constant changes in the interstitial oxygen level and consequently might have caused oscillations in biofilm dissolved oxygen which might hinder the biological yield. Later, the composting matrix cooled down and airflow fluctuations decreased until reaching an oxygen concentration over $12 \%$. From that moment a constant low flow was set until the end of the process.

\subsection{Temperature controller}

The temperature and airflow profiles obtained for control strategy based on airflow regulation from temperature measure are showed in Fig. 5(b). The OUR determined during the period with constant high airflow is also shown. According to previous studies [16], the sensing unit was placed at a middle layer of the matrix. Hereby, a moderate or an excessive airflow rate due to the temperature gradient along the reactor could be minimized. After starting the test with the temperature controller, a rapid decrease of the oxygen level until $0 \%$ was produced without increasing temperature. For this reason, it was necessary to begin the experiment with the oxygen controller until the thermophilic temperatures were achieved. Shortly before the third day of process, the temperature controller was started-up. Then temperature had already reached $60^{\circ} \mathrm{C}$ and therefore, the maximum airflow was applied. Over the next six days, the airflow was always high so the energy cost increased significantly. In a previous work [42] it already was observed that high airflows were needed to maintain the temperature below $55^{\circ} \mathrm{C}$. As it happened in the oxygen controller study, while maintaining the airflow constant, the system dynamics were in pseudo-steady-state conditions. Thus, the OUR profile during the maximum activity phase could be determined. Until the ninth day, the temperature controller was unable to cool the material. Next, during a short time $(24 \mathrm{~h})$ the temperature was kept around the set point fixed by manipulating the airflow. Finally, the material cooled with a low airflow, whereas the oxygen content increased until almost $20.9 \%$. This control strategy is only useful in the exothermic decomposition phase when high temperatures are reached. There is a risk of not supplying enough oxygen to maintain aerobic conditions when working at temperatures below 
the set point although at industrial scale facilities the thermal inertia of the material prevents this situation.

\subsection{Cycles controller}

Fig. 5(c) shows the effects of a predefined cyclic aeration in the temperature evolution. As can be seen, the thermophilic range was registered after the first day of the process. Temperature rapidly reached over $60^{\circ} \mathrm{C}$ and was maintained high until the tenth day. After, the temperature began to decrease gradually. Despite of the wide difference between the high and the low flow applied, the airflow cycles did not cause temperature oscillations, whereas high oxygen fluctuations were produced. A sub-graph is inserted in Fig. 5(c) to represent the cyclic airflow during a short period of time.

\subsection{OUR controller}

The OUR controller strategy was undertaken in duplicate to prove the reproducibility of the system. As explained before, inlet airflow was adjusted from the previous data of OUR and airflow to optimize the next OUR measure (Fig. 2). The resultant temperature, OUR and airflow profiles for both replicates are given in Fig. 6(a) and (b). In both cases, a similar evolution of the three parameters registered was observed during the 20 days of process. The airflow regulation did not present the fluctuations observed in the other studied controllers. The measure of biological activity had an inverse trend than the oxygen content in the exhaust gases, which during the high activity phase was always between 5 and $15 \%$. As can be seen, the biological activity increased in the first stage of the process. The maximum value was reached after 24 hours of starting the composting experiment and was close to $15 \mathrm{~g} \mathrm{O}_{2} \mathrm{~h}^{-1}$. This was maintained during a short period of time, in which the airflow was also maximum. The temperature profile, excepting in the cooling phase, was similar to that of the other controllers studied, with a rapid increase of temperature during the first days to achieve $70^{\circ} \mathrm{C}$. In one replicate, the high temperature was maintained during 12 days (Fig. 6(a)), whereas in the other, the temperature began to decrease after 10 days (Fig. 6(b)). It could be observed that, in both cases, temperature 
was maintained high for a large time while the biological activity decreased. It confirms the importance of the biological activity measure as a composting process indicator, since temperature can be maintained for a long time in the absence of biological activity, given the thermal insulation of composting reactors and the low thermal conductivity of organic matter [43]. After the period of maximum activity related to the availability of the more biodegradable compounds, the temperature, the biological activity (i.e. OUR) and the applied airflow gradually decreased. Only in the cooling phase of these experiments, in the change of thermophilic to mesophilic stage, the temperature remained stable almost three days. Thus, the airflow supplied was not excessive and did not help to cool the system to the conditions when the thermophilic microorganisms became less competitive and were replaced by the mesophilic bacteria again.

\subsection{Controllers comparison}

The main parameters evaluated for each composting system are reported in Table 3. Energy consumption, $\mathrm{OUR}_{\max }$ and $\mathrm{AT}_{\mathrm{u}}$ were data calculated in order to compare the yield of each system. For the cycles aeration only energy consumption is presented because the short period of constant airflow did not permit to calculate $\mathrm{AT}_{\mathrm{u}}$ from the global mass balance. Results for the $\mathrm{O}_{2}$ feedback controller showed the highest $\mathrm{OUR}_{\max }$ when applying constant airflow of $3 \mathrm{~L} \mathrm{~min}^{-1}$ but a lower total cumulative consumption than OUR controllers. Temperature feedback system showed a total oxygen consumption lower than both OUR systems, instead it presented a similar $\mathrm{OUR}_{\max }$ in the constant airflow period. However it is possible that maximum reaction rate was achieved previously in the initial oxygen control period. As expected, temperature controller presented the highest energy requirements.

The determination of the initial and final DRI (Table 3) allowed knowing the stability degree reached in each composting trial. Although not statistically compared, OUR control strategy provided the most stable final products. When applying the other three control strategies a similar stability product was obtained, with a respiration index slightly higher than the OUR controllers final product. 
From the qualitative classification of the respiration indices established by [32], the initial sample could be classified as a waste with a moderate biodegradability, i.e. its DRI was between 2 to $5 \mathrm{mg} \mathrm{O}_{2} \mathrm{~g} \mathrm{OM}^{-1} \mathrm{~h}^{-1}$. Following the same classification, all the final products obtained could be included inside the range of wastes with a low biodegradability. In fact, the $\mathrm{O}_{2}$ system final product was close to the threshold among moderate and low biodegradability, whereas the DRI of the OUR controllers presented an index near to the stability limit of $1 \mathrm{mg} \mathrm{O}_{2} \mathrm{~g} \mathrm{OM}^{-1} \mathrm{~h}^{-1}$ indicated by [33]. It means that in a same period, the OUR controller was able to get a more stable final product than the usual composting controllers with the same process length.

In general, the high temperatures reached during all the composting experiments ensured the elimination of pathogens since, according to $[21,44] 3-4$ days at $55^{\circ} \mathrm{C}$ are enough for their total elimination. These temperatures registered during the thermophilic phase suggested a high biological activity and low dissolved oxygen concentrations in biofilm. As mentioned before, different works have recommended oxygen levels between 5 and $15 \%$ as the optimum range [29]. However, Richard et al. [27] found a higher biodegradation rate when oxygen concentration decreased under thermophilic conditions. The airflow fluctuations applied in the conventional control strategies produced dramatic oscillations in exhaust gas oxygen content indicating a high variability of oxygen profile in the reactor. These oxygen concentration variations could influence the diffusion driving force to the biofilm [6]. The oxygen oscillations did not occur with the OUR control and the oxygen profile was always maintained in an optimum range. As DRI and $\mathrm{AT}_{\mathrm{u}}$ results shown, the most stable material was produced when applying both OUR controllers. Probably, this can be attributed to two factors: (1) the biological activity is optimized along all the experiment and (2) the problems of microbial adaptation due to the oxygen fluctuations are avoided.

Finally, one would expect higher OUR values all through the process when using an OURbased controller. The OUR profiles obtained in the experiments presented here can only be compared in the high-rate decomposition phase; and all control strategies led to similar OUR values thus showing no advantage of the OUR-based strategy. It can be accepted that during this high-rate phase, biological activity is maximum and oxygen concentration in biofilm is 
negligible. Thus it can be hypothesized that oxygen transfer from gas phase to biofilm is the limiting step. This was not confirmed in this work due to the narrow airflow range applied in these experiments and the short time periods with constant aeration. Further research is needed to evaluate the influence of airflow in mass transfer phenomenon when considering the physical limits of the composting process.

Back to the results obtained, it can be concluded that during this moment the OUR is maximized in all systems when enough aeration is provided. The OUR controller is able to adjust the minimum airflow required. Additionally, and from the overall results previously described, it can be assumed that the OUR controller maximizes OUR in the rest of the experiment thus improving the composting process performance.

\section{Conclusions}

The assessment of the three typical composting control systems and a new strategy developed based on OUR have been successfully undertaken. Temperature profiles were very similar in all the systems. Total airflow applied together with the on-line and off-line biological measurements allowed to demonstrate that the OUR control optimizes the biological activity and the material stabilization with a low energy consumption.

\section{Acknowledgements}

Authors thank the financial support provided by the Spanish Ministerio de Ciencia e Innovación (Project CTM2009-14073-C02-01).

\section{References}

[1] R.T. Haug, The Practical Handbook of Compost Engineering. Lewis Publishers, Florida, USA, 1993.

[2] L. Ruggieri, T. Gea, M. Mompeó, T. Sayara, A. Sánchez, Performance of different systems for the composting of the source-selected organic fraction of municipal solid waste. Biosyst. Eng. 101 (2008) 78-86. 
[3] M. Gao, B. Li, A. Yu, F. Liang, L. Yang, Y. Sun, The effect of aeration rate on forcedaeration composting of chicken manure and sawdust. Bioresource Technol. 101 (2010) 1899-1903.

[4] M.J. Diaz, E. Madejon, F. Lopez, R. Lopez, F. Cabrera, Optimization of the rate vinasse/grape marc for co-composting process. Process Biochem. 37 (2002) 1143-1150.

[5] G.A. Kuter, H.A.J. Hoitink, L.A. Rossman, Effects of aeration and temperature on composting of municipal sludge in a full-scale vessel system. J. Water Pollut. Control Fed. 57 (1985) 309-315.

[6] E.K. Papadimitriou, W. Bidlingmaier, T. Gea, Fundamentals in selecting input and output variables for composting process automatic controllers. Compost Sci. Util. 18 (2010) 6-21.

[7] R. Kulcu, O. Yaldiz, Determination of aeration rate and kinetics of composting some agricultural wastes. Bioresource Technol. 93 (2004) 49-57.

[8] M. Rasapoor, T. Nasrabadi, M. Kamali, H. Hoveidi, The effects of aeration rates on generated compost quality, using aerated static pile method. Waste Manage. 29 (2009) $570-573$.

[9] Q.H. Bari, A. Koenig, T. Guihe, Kinetic analysis of forced aeration composting. I. Reaction rates and temperature. Waste Manage. Res. 18 (2000) 303-312.

[10] I. Körner, J. Braukmeier, J. Herrenklage, K. Leikam, M. Ritzkowski, M. Schlegelmilch, R. Stegmann, Investigation and optimization of composting processes - Test systems and practical examples. Waste Manage. 23 (2003) 17-26.

[11] A. de Guardia, C. Petiot, D. Rogeau, Influence of aeration rate and biodegradability fractionation on composting kinetics. Waste Manage. 28 (2008) 73-84.

[12] K. Ekinci, H.M. Keener, D. Akbolat, Effects of feedstock, airflow rate, and recirculation ratio on performance of composting systems with air recirculation. Bioresource Technol. 97 (2006) 922-932.

[13] M.S. Finstein, F.C. Miller, P.F. Strom, Waste treatment composting as a controlled system, in: H.J. Rehm, G. Reed, (Eds), Biotechnology, VCH Verlagsgesellschaft, Weinheim, Germany, Vol. 8, 1986, pp. 363-398. 
[14] M.S. Finstein, J.A. Hogan, Integration of composting process microbiology, facility structure and decision-making. in: H.A.J. Hoitink, H.M. Keener, (Eds), Science and Engineering of Composting: Design, Environmental, Microbiological and Utilization Aspects, Renaissance Publ. Columbus, Ohio, 1993, pp. 1-23.

[15] E.I. Stentiford, Composting control: principles and practice. in: M. de Bertoldi, P. Sequi, B. Lemmes, T. Papi (Eds.), The Science of Composting, Blackie Academic \& Professional, Glascow, UK. pp 49-59, 1996.

[16] K. Ekinci, H.M. Keener, D. Akbolat, Effect of thermocouple location on the optimum composting rate. Biosyst. Eng. 89 (2004) 345-353.

[17] S.T. MacGregor, F.C. Miller, K.M. Psarianos, M.S. Finstein, Composting process control based on interaction between microbial heat output and temperature. Appl. Environ. Microbiol. 41 (1981) 1321-1330.

[18] P.D. Bach, K. Nakasaki, M. Shoda, H. Kubota, Thermal balance in composting operations. J. Ferment. Technol. 65 (1987) 199-209.

[19] T. Gea, R. Barrena, A. Artola, A. Sánchez, Optimal bulking agent particle size and usage for heat retention and disinfection in domestic wastewater sludge composting. Waste Manage. 27 (2007) 1108-1116.

[20] C. Liang, K.C. Das, R.W. McClendon, The influence of temperature and moisture contents regimes on the aerobic microbial activity of a biosolids composting blend. Bioresource Technol. 86 (2003) 131-137.

[21] The U.S. Environmental Protection Agency. A Guide to the Biosolids Risk Assessments for the EPA Part 503 Rule. http://www.epa.gov/region8/water/biosolids/pdf/625R92013ALL.pdf, 1995.

[22] M.A. Bustamante, R. Moral, C. Paredes, M.C. Vargas-García, F. Suárez-Estrella, J. Moreno, Evolution of the pathogen content during co-composting of winery and distillery wastes. Bioresource Technol. 99 (2008) 7299-7306.

[23] K. Das, H.M. Keener, Numerical model for the dynamic simulation of a large scale composting system. T. ASAE. 40 (1997) 1179-1189. 
[24] F.C. Miller, Composting as a process based on the control of ecologically selective factors. In: F.B. Meeting (Ed.), Soil Microbial Ecology, Markel Dekker, Inc., New York, USA, pp. 515-544, 1992.

[25] A.M.T. Magalhaes, P.J. Shea, M.D. Jawson, E.A. Wicklund, D.W. Nelson, Practical simulation of composting in the laboratory. Waste Manage. Res. 11 (1993) 143-154.

[26] M. de Bertoldi, A. Rutili, B. Citterio, M. Civilini, Composting management: a new process control through $\mathrm{O}_{2}$ feesback. Waste Manage. Res. 6 (1988) 239-259.

[27] T.L. Richard, L.P. Walker, J.M. Gosset, Effects of oxygen on aerobic solid-state biodegradation kinetics. Biotechnol. Progr. 22 (2006) 60-69.

[28] W. Wang, X. Wang, J. Liu, M. Ishii, Y. Igarashi, Z. Cui, Effect of oxygen concentration on the composting process and maturity. Compost Sci. Util. 15 (2007) 184-190.

[29] T.G. Leton, E.I. Stentiford, Control of aeration in static pile composting. Waste Manage. Res. 8 (1990) 299-306.

[30] M. Lawrynczuk, Modelling and nonlinear predictive control of a yeast fermentation biochemical reactor using neural networks, Chem. Eng. J. 145 (2008) 290-307.

[31] E. Giusti, S. Marsili-Libelli, Fuzzy modeling of the composting process. Environ. Modell. Softw. 25 (2010) 641-647.

[32] S. Ponsá, T. Gea, A. Sánchez, Different indices to express biodegradability in organic solid wastes. J. Environ. Qual. 39 (2010) 706-712.

[33] F. Adani, C. Ubbiali, P. Genevini, The determination of biological stability of composts using the Dynamic Respiration Index: the results of experience after two years. Waste Manage. 26 (2006) 41-48.

[34] The U.S. Department of Agriculture and The U.S. Composting Council, Test Methods for the Examination of Composting and Compost, Edaphos International, Houston, TX, USA, 2001.

[35] L. Ruggieri, T. Gea, A. Artola, A. Sánchez, Air filled porosity measurements by air pycnometry in the composting process: A review and a correlation analysis. Bioresource Technol. 100 (2009) 2655-2666. 
[36] L. Ruggieri, T. Gea, A. Artola, A. Factors affecting air pycnometer performance for its use in the composting process. Compost Sci. Util. 17 (2009) 266-275.

[37] O. Levenspiel, Chemical reaction engineering, third ed., John Wiley and Sons, New York, USA, 1999.

[36] E. T. van der Laan, Notes of the diffusion type model for longitudinal mixing in flow. Chem. Eng. Sci. 7 (1958) 187-191.

[39] O. Levenspiel, Modeling in chemical engineering. Chem. Eng. Sci. 57 (2002) 4691-4696.

[40] A. Tremier, A. de Guardia, C. Massiani, J.L. Martel, Influence of the Airflow Rate on Heat and Mass Transfers during Sewage Sludge and Bulking Agent Composting . Environ. Technol., 26 (2005) 1137-1150.

[41] A. Tremier, F. Hénon, G. Debenest, J.L. Martel, M. Quintard, Use of a gas tracing method to diagnose the aeration system in a large scale composting process. In: L. Rodic-Wiersma, J. Barth, W. Bidlingmaier, M. de Bertoldi, L. Diaz, (Eds.), Proceedings of ORBIT 2008, Wageningen, The Netherlands, 2008.

[42] R. Barrena, A. Artola, F. Vázquez, A. Sánchez, The use of composting for the treatment of animal by-products: Experiments at lab scale. J. Hazard. Mater. 161 (2009) 380-386.

[43] R. Barrena, C. Cánovas, A. Sánchez, Prediction of temperature and thermal inertia effect in the maturation stage and stockpiling of a large composting mass. Waste Manage. 26 (2006) 953-959.

[44] J. López-Real, M. Foster, Plant pathogen survival during the composting of agricultural waste, in: J.K.R. Gasser (Ed.), Elsevier applied science publishers, London, UK, 1985, pp. 291-302. 
Tables

Table 1: Results for Residence Time Distribution analysis and the dispersion number determined for an airflow range of 1 to $10 \mathrm{Lmin}^{-1}$.

\begin{tabular}{llll}
\hline $\begin{array}{l}\text { Flow } \\
\left(\mathrm{L} \mathrm{min} \text { min }^{-1}\right)\end{array}$ & $\begin{array}{l}\mathrm{t}_{\mathrm{m}} \\
(\mathrm{min})\end{array}$ & $\sigma^{2}$ & $\mathrm{D} / \mathrm{uL}$ \\
\hline 1 & 37.96 & 176.41 & 0.07 \\
2 & 18.88 & 38.99 & 0.06 \\
3 & 11.81 & 16.42 & 0.06 \\
5 & 7.36 & 5.97 & 0.06 \\
8 & 4.71 & 1.66 & 0.04 \\
10 & 3.83 & 0.92 & 0.03 \\
\hline
\end{tabular}

$\mathrm{t}_{\mathrm{m}}$ : mean residence time; $\sigma^{2}$ : variance; D/uL: dispersion number. 
Table 2: Characterization of the initial OFMSW and the final products obtained after each composting trial.

\begin{tabular}{llll}
\hline Material & $\begin{array}{l}\text { Dry Matter } \\
(\%, \mathrm{wb})\end{array}$ & $\begin{array}{l}\text { Organic Matter } \\
(\%, \mathrm{db})\end{array}$ & $\begin{array}{l}\text { TOC } \\
(\%, \mathrm{db})\end{array}$ \\
\hline Initial OFMSW & $47.0 \pm 0.4$ & $76.4 \pm 4.7$ & $43.1 \pm 2.1$ \\
\hline Oxygen controller & $40.5 \pm 4.8$ & $69.0 \pm 5.6$ & $38.2 \pm 3.4$ \\
Temperature controller & $39.7 \pm 2.3$ & $74.6 \pm 6.4$ & $38.7 \pm 0.4$ \\
Cycles controller & $45.2 \pm 1.8$ & $69.9 \pm 7.3$ & $38.7 \pm 5.4$ \\
OUR controller (I) & $42.2 \pm 1.6$ & $67.0 \pm 4.6$ & $33.4 \pm 2.1$ \\
OUR controller (II) & $42.4 \pm 3.0$ & $65.9 \pm 3.6$ & $33.8 \pm 2.5$
\end{tabular}

DM: Dry Matter; OM: Organic Matter; TOC: Total Organic Carbon; wb: wet basis; db: dry basis. 
Table 3: Parameters evaluated for each composting system.

\begin{tabular}{|c|c|c|c|c|c|}
\hline $\begin{array}{l}\text { Control } \\
\text { System } \\
\end{array}$ & $\begin{array}{l}\text { Energy } \\
\text { Consumption }(k J)\end{array}$ & $\begin{array}{l}\mathbf{O U R}_{\max } \\
\left(\mathrm{g} \mathrm{O}_{2} \mathbf{h}^{-1}\right) \\
\end{array}$ & $\begin{array}{l}\mathbf{A T u} \\
\left(\mathrm{g} \mathrm{O}_{2}\right)\end{array}$ & $\begin{array}{l}\text { Initial DRI } \\
\left(\mathrm{mg} \mathrm{O}_{2} \mathrm{~g} \mathrm{OM}^{-1} \mathrm{~h}^{-1}\right)\end{array}$ & $\begin{array}{l}\text { Final DRI } \\
\left(\mathrm{mg} \mathrm{O}_{2} \mathrm{~g} \mathrm{OM}^{-1} \mathrm{~h}^{-1}\right)\end{array}$ \\
\hline Oxygen & $14.3 \cdot 10^{3}$ & 20.0 & 2386 & & $1.93 \pm 0.32$ \\
\hline Temperature & $22.6 \cdot 10^{3}$ & 14.8 & 2191 & & $1.65 \pm 0.08$ \\
\hline Cycles & $11.5 \cdot 10^{3}$ & - & - & $4.07 \pm 0.33$ & $1.71 \pm 0.01$ \\
\hline OUR I & $11.9 \cdot 10^{3}$ & 14.5 & 2891 & & $1.47 \pm 0.28$ \\
\hline OUR II & $16.2 \cdot 10^{3}$ & 13.9 & 2562 & & $1.29 \pm 0.05$ \\
\hline
\end{tabular}

OUR $_{\max }$ : maximum Oxygen Uptake Rate achieved (in the period of constant airflow for oxygen and temperature controllers); $\mathrm{AT}_{\mathrm{u}}$ : total cumulative oxygen uptake; DRI: Dynamic Respiration Index average during 24 hours of maximum activity. 


\section{Figures}

Fig. 1: Experimental set up of the composting pilot reactor.

Fig. 2. Scheme of control laws for the OUR controller.

F: airflow; OUR: Oxygen Uptake Rate.

Fig. 3: RTD curves for different airflow applied.

Fig. 4: Comparison of RTD curves obtained for low and high airflow in the reactor filled at 80 and $100 \%$ of total matrix volume.

Fig. 5: Evolution of temperature and airflow applied for the three usual systems used to regulate the airflow in the composting process. Oxygen Uptake Rate measure is only represented in a long period of constant aeration, which was found during the high-rate stage of the oxygen and temperature controllers.

Fig. 6: Evolution of temperature, Oxygen Uptake Rate and airflow in the two composting experiments undertaken by means of the OUR controller to supply the oxygen necessary. 


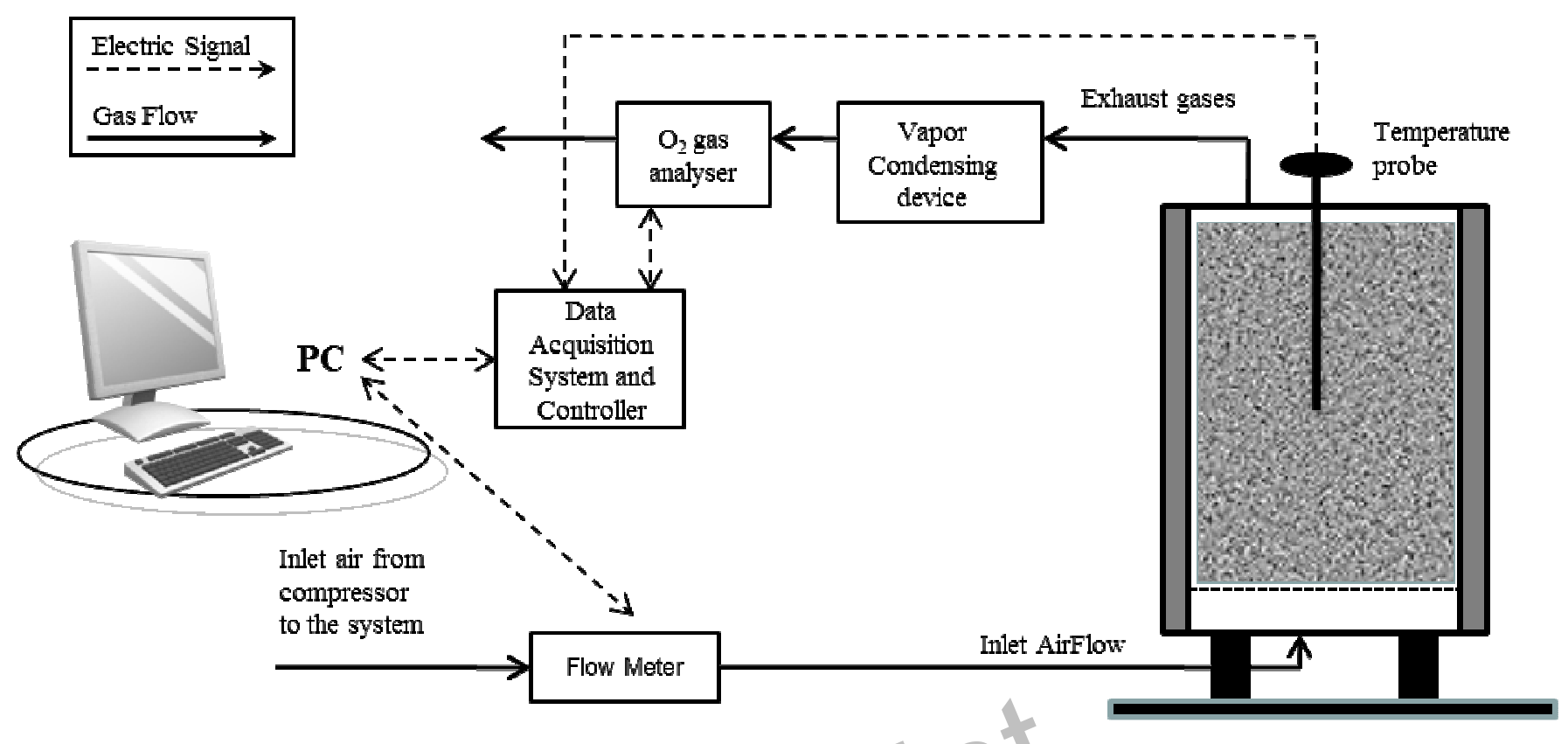

Fig. 1: Experimental set up of the composting pilot reactor. 


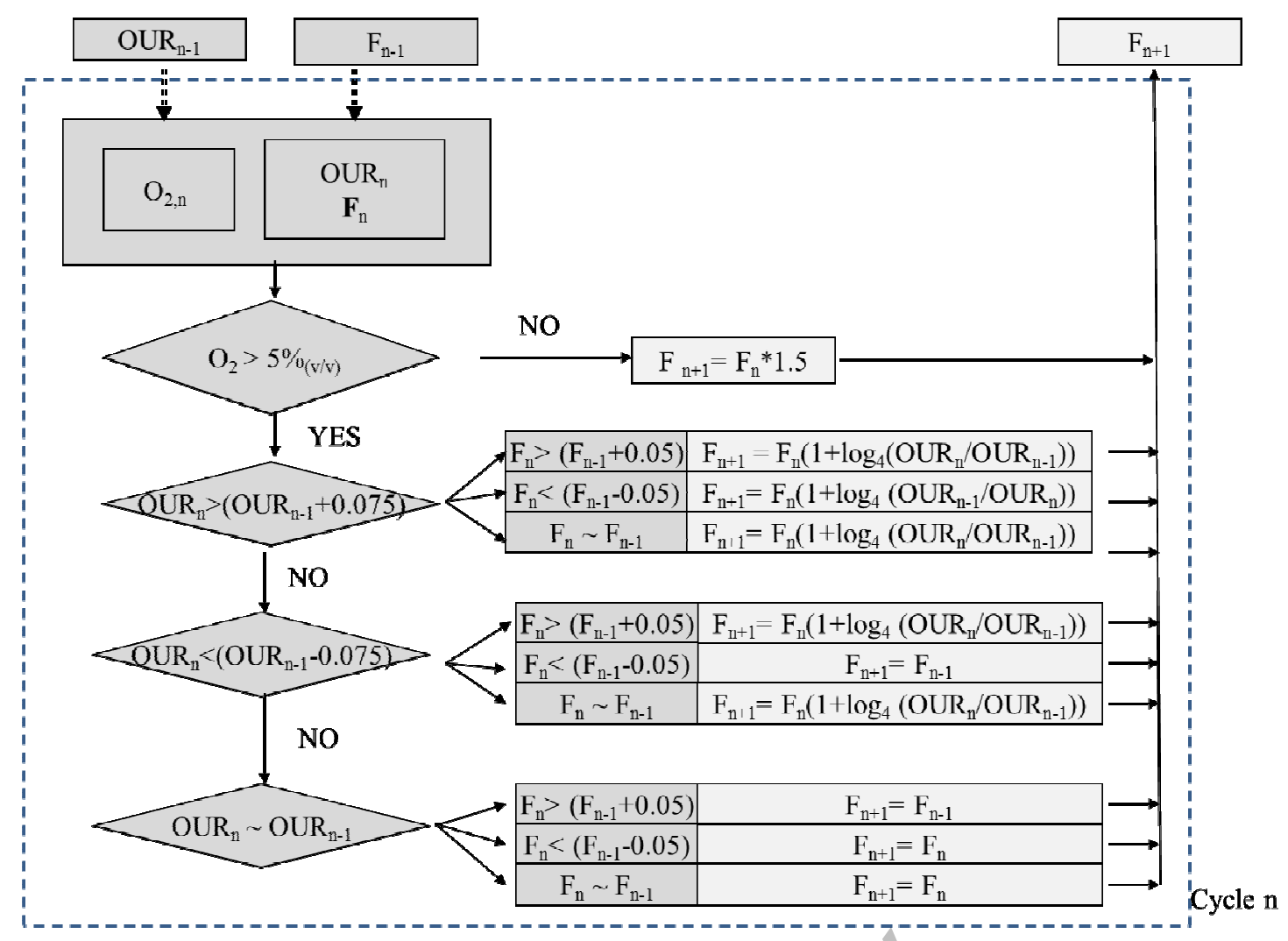

Fig. 2. Scheme of control laws for the OUR controller.

F: airflow; OUR: Oxygen Uptake Rate. 


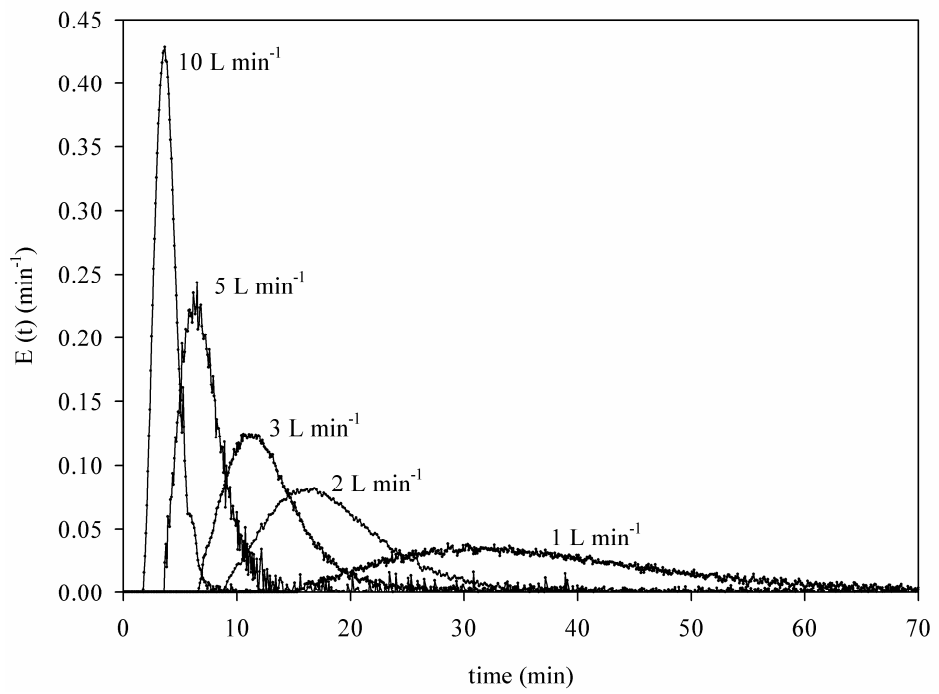

Fig. 3: RTD curves for different airflow applied. 

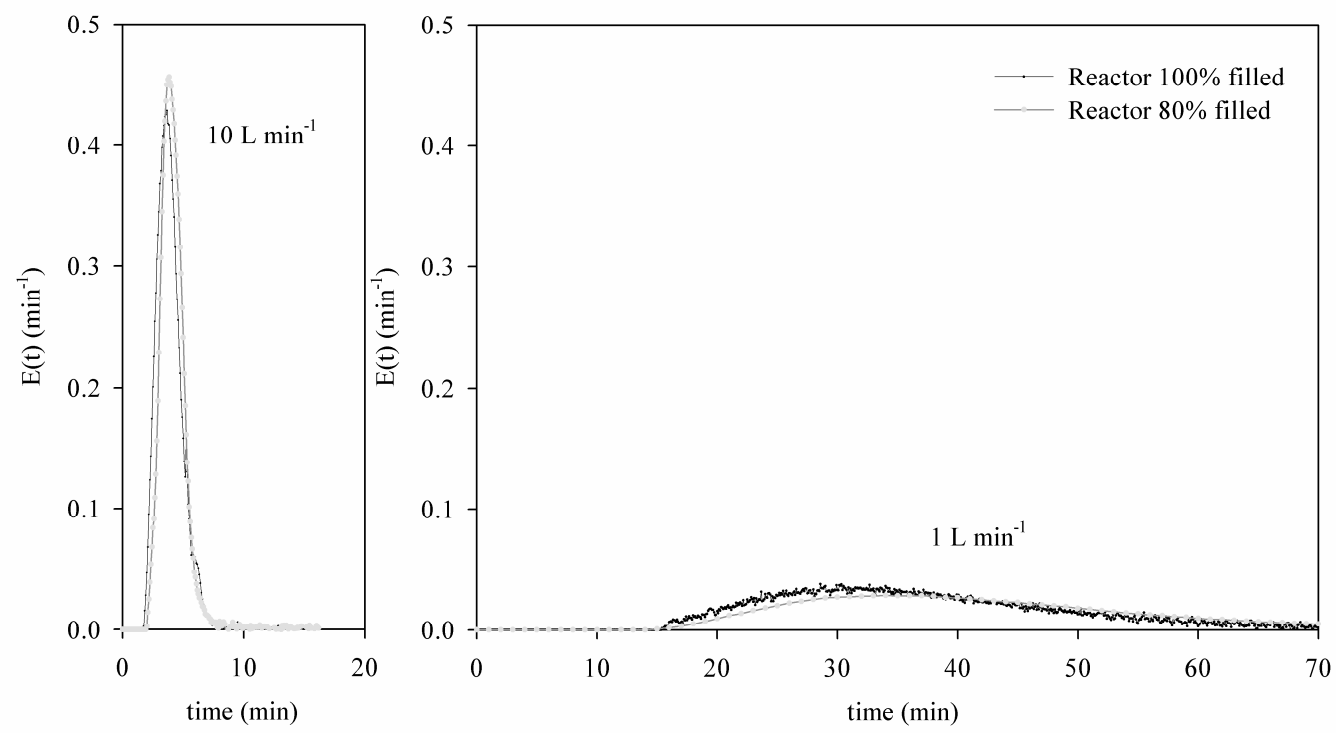

Fig. 4: Comparison of RTD curves obtained for low and high airflow in the reactor filled at 80 and $100 \%$ of total matrix volume. 

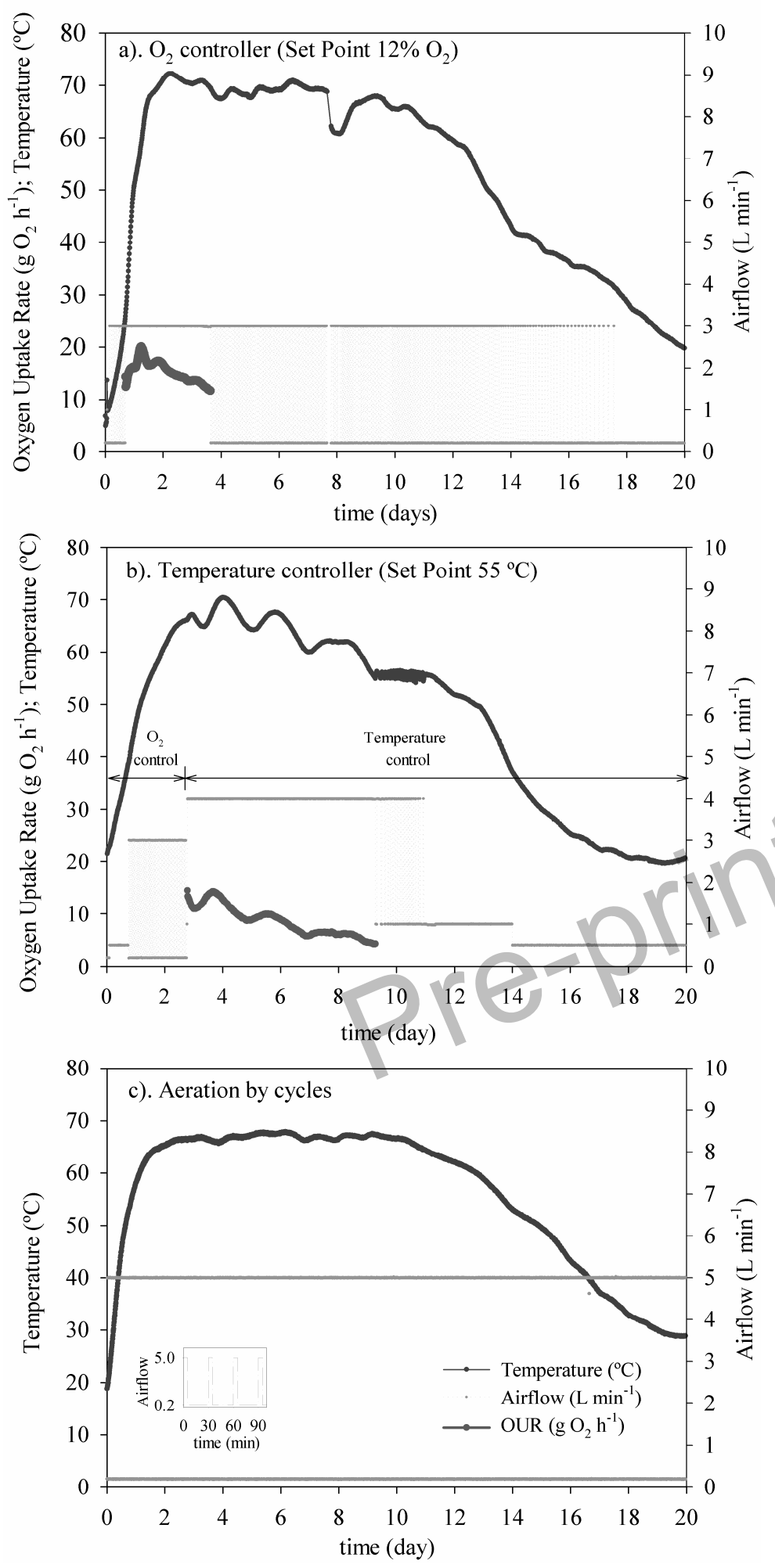

Fig. 5: Evolution of temperature and airflow applied for the three usual systems used to regulate the airflow in the composting process. Oxygen Uptake Rate measure is only represented in a long period of constant aeration, which was found during the high-rate stage of the oxygen and temperature controllers. 

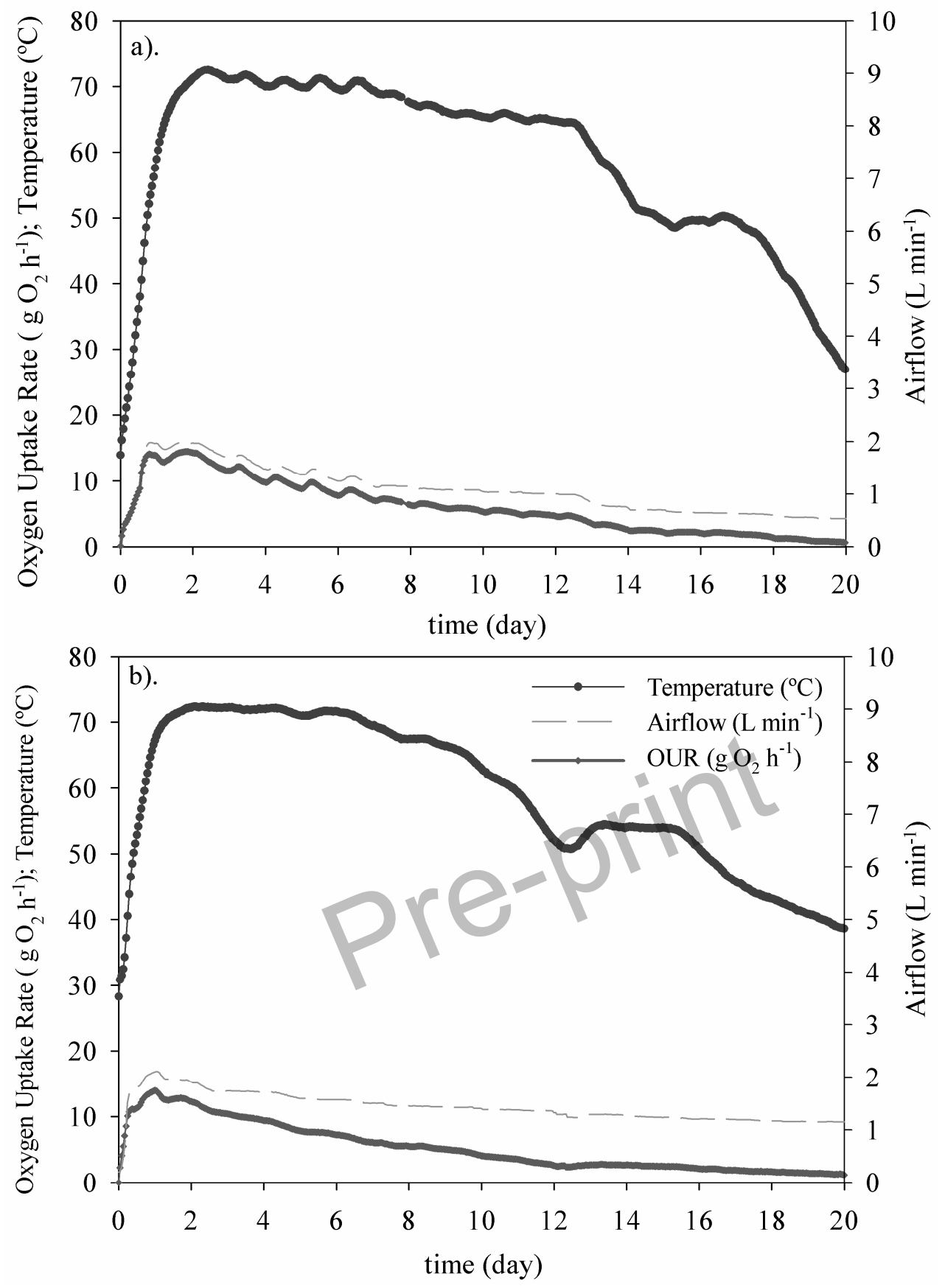

Fig. 6: Evolution of temperature, Oxygen Uptake Rate and airflow in the two composting experiments undertaken by means of the OUR controller to supply the oxygen necessary. 